\title{
Differences in Compensation Satisfaction Pertaining to the Use Pattern of Skin Care Clinics
}

\author{
Misuk Shin \\ Department of Beauty Design, Wonkwang University, Iksan-si, Jeollabuk-do, Korea
}

Corresponding author: Misuk Shin, Department of Beauty Design, Wonkwang University, 460 Iksan-daero, Iksan-si, Jeollabuk-do 54538, Korea

Fax: +82 29407826

Email: 1122sin@hanmail.net

Received December 27, 2016

Revised June 9, 2017

Accepted June 26, 2017

Published September 30, 2017

\begin{abstract}
Purpose: This study examined the effects of the women's use pattern of skin care clinics on compensation satisfaction with the aim of enhancing the quality of such facilities and systemizing their compensation programs for providing better services. The study findings will be used as training materials and marketing aids by clinics and startups to build their trust with customers. Methods: The data for this study were collected over a period of 2 months from July 6 to September 5, 2015. The questionnaires were administered to adult women residing in Seoul who visited skin care clinics. Among the distributed 282 questionnaires, 82 questionnaires with inadequate responses were excluded and 200 questionnaires were used as the final data. Results: The type and one-time fee of skin care clinics significantly affected the difference in the women's compensation satisfaction depending on their use pattern of skin care clinics. No marked difference in compensation satisfaction was noted with respect to the information source and visit frequency. Conclusion: Thus, to improve compensation satisfaction depending on the women's use pattern of skin care clinics, their reliability as well as empathy toward them should be enhanced rather than simply increasing tangibility, responsiveness, and assurance.
\end{abstract}

Keywords: Skin care clinics, Compensation satisfaction, Compensation program, Reliability, Responsiveness

\section{Introduction}

현재의 피부 미용 산업은 2008년 국가 자격증의 시행으로 성장 하였으며, 2013년 기준 전국에 분포된 피부 관리실은 전년 대비 148 개가 증가하여 15,511 개, 관리사만도 25,417 명에 달하였다(KOSIS, 2014). 피부 관리실의 증가는 미용 산업 발전의 기반 역할을 한 반 면, 업체 간의 치열한 서비스 경쟁으로 인해 관리실을 찾는 고객 은 고품질, 고차원의 서비스 품질을 요구하게 되었다(Jong \& Kim, 2015). 따라서 끊임없이 변화하는 고객의 요구를 충족시키기 위한 방안으로 관리실을 찾는 고객의 이용형태에 따른 고객 관리가 관리 실에 어떠한 영향을 미치는 가에 대한 연구의 필요성이 제기되었다.

세계적인 라이프 트랜드로 웰빙이 성행하면서 피부 관리는 건강 을 위한 또는 사회 진출을 위한 준비 과정이 되고 있다(Son et al., 2009). 피부 관리는 피부의 기능을 보호하고 유지할 뿐만 아니라 인 체를 아름답고 건강하게 가꾸어 주는 것으로, 피부의 외적인 면과 내적인 면의 건강을 유지하는 목적을 가지고 있다. 현재 피부 관리
실에서는 이러한 피부 관리의 개념을 기반으로 일정한 형태의 프로 그램을 사용하고 있으며, 고객의 피부상태는 물론, 생활습관의 변화 까지도 상담하고 있다.

피부 관리실의 이용고객은 나이별로 특징을 가지고 있으며, 소비 유형이 다양하다. 특히 고객이 피부 관리실을 선택하는데 우선적 고 려사항은 1 회 관리비용 및 관리실 추천경로의 영향이 크다고 하여 (Park, 2015), 피부 관리실을 이용하는 경로를 통해 홍보 및 관리를 할 수 있을 뿐만 아니라 이는 잠재적인 마케팅의 요소로 활용될 수 있음을 알려주고 있다(Lee, 2015).

피부 관리실은 관리를 받는 고객 정보에 따른 보상을 계속해오고 있으며 각기 다른 방법의 유형으로 고객을 관리하여 오고 있다. 최 근 보상 프로그램의 개발과 발전으로, 보상은 고객을 관리하는데 주 요한 마케팅적 요소로 자리 잡고 있다. 보상은 고객의 감성에 도움 이 될 수 있는 여행이나 콘서트 등의 이벤트로 보상을 하는 쾌락적 보상(Dowling \& Uncles, 1997) 등의 다양한 보상 방법이 있으며, 서 비스 보상에 대한 측정은 유형성, 신뢰성, 반응성, 보증성, 공감성의 
5 가지 기준으로 평가하고 있다(Kim \& Jin, 2013). 이러한 보상은 소 비자의 구매행동과 충성도에 영향을 미칠 뿐만 아니라 잠재 고객을 파악할 수 있는 효과를 나타낸다.

선행논문을 보면 피부 관리실의 현황 및 실태(Jang \& Choi, 2006), 피부 관리에 대한 지식과 관리 실태(Jeong \& Yoo, 2003), 직장여성에 관한 피부 관리논문(Jegal \& Kim, 2003), 고객의 특성 에 따른 피부 관리실의 만족도(Kim, 2010; Lee \& Bae, 2011)에 관 한 논문은 많으나, 피부 관리실을 이용하는 형태와 만족도에 관한 연구는 미비한 실정이다.

따라서 본 연구에서는 피부 관리실 이용형태에 따른 보상 만족에 대한 영향을 알아봄으로써 관리실의 질적 향상을 높이고, 관리실의 보 상 프로그램을 체계화하여 고객에게 올바른 서비스를 제공할 뿐만 아 니라 이를 바탕으로 한 교육 자료를 관리실 및 창업을 위한 마케팅으 로 적극 활용하여 고객에 대한 신뢰를 높이는데 도움을 주고자 한다.

본 연구의 연구가설은 다음과 같다.

가설1. 피부 관리실의 이용형태는 유형성에 영향을 줄 것이다. 가설2. 피부 관리실의 이용형태는 신뢰성에 영향을 줄 것이다. 가설3. 피부 관리실의 이용형태는 반응성에 영향을 줄 것이다. 가설4. 피부 관리실의 이용형태는 보증성에 영향을 줄 것이다. 가설5. 피부 관리실의 이용형태는 공감성에 영향을 줄 것이다.

\section{Methods}

\section{1. 연구대상자}

본 연구를 수행하기 위한 자료 수집은 2015년 7월 6일부터 9월
5 일까지 총 2 개월간에 걸쳐 진행되었다. 모집단은 서울에 거주하며 피부 관리실을 이용하는 성인 여성을 대상으로 총 282부의 설문지 를 배포하였다. 배포한 설문지 중 82 부의 부적합한 설문지를 제외하 고 200 부를 회수하여 최종 자료로 사용하였다.

\section{2. 측정도구}

본 연구조사를 위해 사용된 설문지는 피부 관리실 이용에 대한 일반적인 항목에 대한 내용을 시작으로 피부 관리실의 이용형태 와 보상 만족에 대한 설문지로 이루어졌다. 피부 관리실 이용형태 는 Choi \& Yoo (2012)의 연구에서 인용된 척도를 본 연구에 맞게 수정 보완하여 명명척도로 측정하였다. 보상 만족도는 Kim \& Jin (2013)과 Lee \& Jang (2010)의 연구에서 인용된 척도를 본 연구에 맞게 수정 보완하여 18 문항에 리커트 5 점 척도로 측정하였다. 1점 은 ‘전혀 그렇지 않다'에서 5점은 ‘항상 그렇다’로 숫자가 높을수록 보상 만족도가 낮음을 의미한다.

\section{3. 자료처리 및 분석방법}

본 연구를 수행하는데 있어서 자료는 다음과 같은 통계처리 과정 을 거쳤다.

1) 조사대상자의 일반적 특성, 피부 관리실 이용형태를 알아보기 위하여 빈도분석(frequency analysis)을 실시하였다.

2) 보상에 대한 만족도에 대한 신뢰도는 Cronbach's $\alpha$ 로 판단하였다.

3) 조사대상자의 피부 관리실 이용형태에 따른 보상에 t-test 와 일원변량분석(one-way analysis of variance)을 실시하였으며, Scheffe의 다중범위 검정(Scheffe's multiple range test)을 통하여 $p<0.05$ 에서 유의한 차이를 검정하였다.

Table 1. Subject characteristics

\begin{tabular}{|c|c|c|c|}
\hline Category & & Frequency $(\mathrm{N})$ & Percentage (\%) \\
\hline \multirow{2}{*}{ Age (years) } & $21-30$ & 134 & 67.0 \\
\hline & $31-40$ & 66 & 33.0 \\
\hline \multirow{2}{*}{ Marital status } & Single & 163 & 81.5 \\
\hline & Married & 37 & 18.5 \\
\hline \multirow{6}{*}{ Occupation } & Homemaker & 5 & 2.5 \\
\hline & Professional & 26 & 13.0 \\
\hline & Student & 96 & 48.0 \\
\hline & Service sector & 47 & 23.5 \\
\hline & Office worker & 22 & 11.0 \\
\hline & Others & 4 & 2.0 \\
\hline \multirow{3}{*}{ Education } & High school graduate & 14 & 7.0 \\
\hline & College student/graduate & 58 & 29.0 \\
\hline & University student/graduate & 128 & 64.0 \\
\hline Total & & 200 & 100.0 \\
\hline
\end{tabular}




\section{Results and Discussion}

\section{1. 일반적 특성}

조사대상자의 일반적 특성을 살펴본 결과는 Table 1 와 같다. 연령 은 '21-30세’가 67.0\%, '31-40세’가 33.0\%이었고, 결혼 상태는 '미혼' 이 $81.5 \%$, ‘기혼’이 $18.5 \%$ 이었다. 직업은 ‘학생’이 $48.0 \%$ 로 가장 많았 고, '서비스직'이 $23.5 \%$, '전문직'이 $13.0 \%$, '사무직'이 $11.0 \%$, '전업주 부'가 $2.5 \%$, '기타'가 $2.0 \%$ 순이었으며, 최종학력은 '대학교 재학/졸
업'이 $64.0 \%$,전문대학 재학/졸업'이 $29.0 \%$, '고등학교 졸업'이 $7.0 \%$ 순으로 조사되었다.

\section{2. 피부 관리실의 이용형태}

피부 관리실 이용형태를 살펴본 결과는 Table 2 와 같다. 피부 관 리실에 대한 정보습득 경로는 '타인의 권유'가 $38.0 \%$ 로 가장 많았 고, '인터넷' $36.5 \%$, '기타' $9.0 \%$, '전단지 및 지역 정보지' $6.5 \%$, '간 판' $5.5 \%$ 순이었으며, 이용하는 피부 관리실 형태는 '일반 피부 관

Table 2. Use pattern of skin care clinics

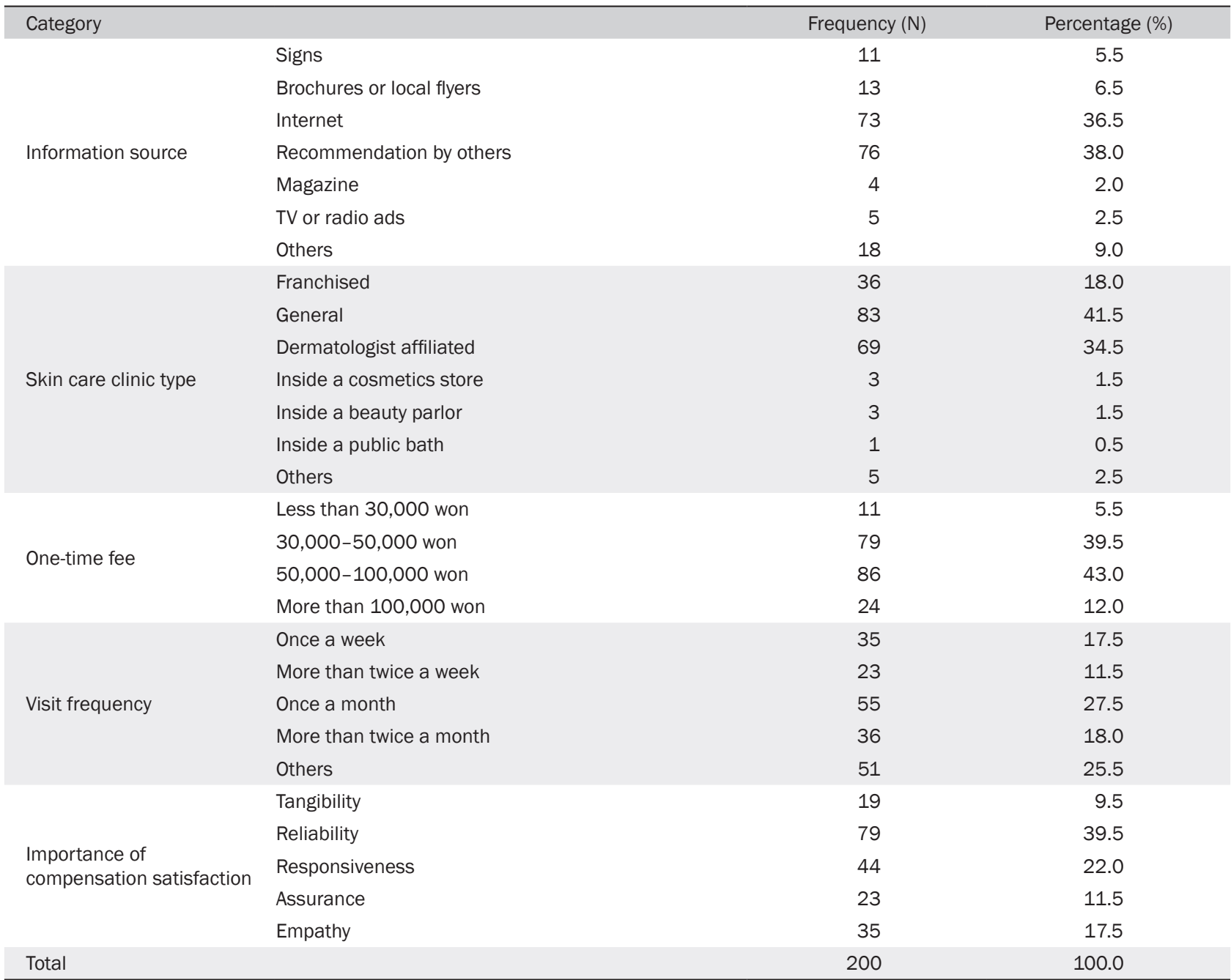

Table 3. Survey reliability

\begin{tabular}{llcc}
\hline Component & Criteria & Number of questions & Cronbach's $\alpha$ \\
& Tangibility & 0.814 & 4 \\
& Reliability & 0.897 & 4 \\
Compensation satisfaction & Responsiveness & 0.816 & 4 \\
& Assurance & 3 & 5.88 \\
& Empathy & 0.831 & 5 \\
& Total & 0.943 & 20 \\
\hline
\end{tabular}


리실' $41.5 \%$, '피부과 제휴 피부 관리실' $34.5 \%$, ‘프랜차이즈 피부 관 리실' $18.0 \%$ 순이었다. 1회 피부 관리 비용으로는 '5-10만원 미만'이 $43.0 \%, 3-5$ 만원 미만'이 $39.5 \%$, '10만원 이상'이 $12.0 \%$ 순이었고, 피 부 관리실 방문 빈도는 ‘월 1회’가 $27.5 \%$, '월 2회 이상'이 $18.0 \%$, '주1 회'가 $17.5 \%$, '주 2회 이상'이 $11.5 \%$ 순이었으며, 가끔 방문한다와 같 은 '기타'는 $25.5 \%$ 이었다. 보상에 대한 만족도에서 가장 중요하게 생 각하는 부분으로는 '신뢰성'이 $39.5 \%$, '반응성'이 $22.0 \%$, '공감성'이 $17.5 \%$, '보증성'이 $11.5 \%$, '유형성'이 $9.5 \%$ 순으로 나타났다.

\section{3. 설문지의 신뢰도 분석}

본 연구의 모형과 가설을 검증하기 전에 측정 항목이 어느 정도 일관성이 있게 측정되었는지 알아보기 위해 먼저 신뢰성을 검토하 였다. 각 변수들 간의 측정 항목 및 Cronbach's $\alpha$ 의 값은 Table 3에
나타나 있으며, 모든 측정항목들의 $\alpha$ 값이 0.70 이상이므로 높은 내 적 일관성을 가진 것으로 평가되어 본 연구에 사용된 측정도구는 신 뢰성을 확보했다고 할 수 있다.

\section{4. 보상 만족도}

보상 만족도의 기술통계를 살펴본 결과는 Table 4 와 같다. 보상 만족도 전체의 평균은 3.04로, '반응성' $(\mathrm{M}=3.11)$, '보증성' $(\mathrm{M}=3.11)$, '공감성' ( $\mathrm{M}=3.06)$, '신뢰성' $(\mathrm{M}=3.04)$, '유형성' $(\mathrm{M}=2.90)$ 순으로 보 상 만족도의 평균이 높았다.

\section{5. 피부 관리실 이용형태에 따른 보상 만족도의 차이}

피부 관리실 이용형태에 따른 보상 만족의 차이를 살펴본 결과는 Table 5 와 같다. 피부 관리실 형태와 1 회 피부 관리 비용에 따른 보

Table 4. Compensation satisfaction statistics

\begin{tabular}{llccccc}
\hline Category & Sub-factors & N & Min. & Max. & Mean & S.D. \\
& Tangibility & 200 & 1.25 & 5.00 & 2.90 & 0.70 \\
& Reliability & 200 & 1.50 & 5.00 & 3.04 & 0.70 \\
& Responsiveness & 200 & 1.33 & 5.00 & 3.11 & 0.65 \\
Compensation satisfaction & Assurance & 200 & 1.00 & 5.00 & 3.11 & 0.71 \\
& Empathy & 200 & 1.00 & 4.50 & 3.06 & 0.62 \\
& Total & 200 & 1.56 & 4.89 & 3.04 & 0.57 \\
\hline
\end{tabular}

N, number of questionnaires; Min., minimum; Max., maximum; S.D., standard deviation.

Table 5. Differences in compensation satisfaction based on use pattern of skin care clinics

\begin{tabular}{|c|c|c|c|c|c|c|c|}
\hline Category & & $\mathrm{N}$ & Mean & S.D. & $F$ & $p$ & Scheffe \\
\hline \multirow{4}{*}{ Information source } & Signs, brochures, or local flyers & 24 & 3.14 & 0.56 & \multirow{4}{*}{1.435} & \multirow{4}{*}{0.234} & \multirow{4}{*}{-} \\
\hline & Internet & 73 & 2.93 & 0.52 & & & \\
\hline & Recommendation by others & 76 & 3.08 & 0.62 & & & \\
\hline & Others & 27 & 3.11 & 0.56 & & & \\
\hline \multirow{4}{*}{ Skin care clinic type } & Franchise (a) & 36 & 3.07 & 0.52 & \multirow{4}{*}{$4.242^{* *}$} & \multirow{4}{*}{0.006} & \multirow{4}{*}{$d>a, b, c$} \\
\hline & General (b) & 83 & 3.07 & 0.60 & & & \\
\hline & Dermatologist affiliated (c) & 69 & 2.91 & 0.49 & & & \\
\hline & Others (d) & 12 & 3.51 & 0.69 & & & \\
\hline \multirow{3}{*}{ One-time fee } & Less than 50,000 won (a) & 90 & 3.21 & 0.58 & \multirow{3}{*}{$10.016^{* * *}$} & \multirow{3}{*}{0.000} & \multirow{3}{*}{$a, c>c, b$} \\
\hline & $50,000-100,000$ won (b) & 86 & 2.84 & 0.53 & & & \\
\hline & More than 100,000 won (c) & 24 & 3.10 & 0.47 & & & \\
\hline \multirow{5}{*}{ Visit frequency } & Once a week & 35 & 3.11 & 0.68 & \multirow{5}{*}{1.899} & \multirow{5}{*}{0.112} & \multirow{5}{*}{-} \\
\hline & More than twice a week & 23 & 3.30 & 0.72 & & & \\
\hline & Once a month & 55 & 2.94 & 0.56 & & & \\
\hline & More than twice a month & 36 & 3.03 & 0.57 & & & \\
\hline & Others & 51 & 2.98 & 0.37 & & & \\
\hline \multirow{5}{*}{$\begin{array}{l}\text { Importance of } \\
\text { compensation satisfaction }\end{array}$} & Tangibility & 19 & 2.84 & 0.56 & \multirow{5}{*}{0.905} & \multirow{5}{*}{0.462} & \multirow{5}{*}{-} \\
\hline & Reliability & 79 & 3.08 & 0.49 & & & \\
\hline & Responsiveness & 44 & 3.10 & 0.73 & & & \\
\hline & Assurance & 23 & 3.03 & 0.66 & & & \\
\hline & Empathy & 35 & 2.98 & 0.45 & & & \\
\hline
\end{tabular}

S.D., standard deviation; ${ }^{* *} p<0.01 ;{ }^{* * *} p<0.001$. 
상 만족의 차이는 유의미하였으나, 피부 관리실 정보습득 경로, 방 문 빈도, 보상에 대한 만족도에서 가장 중요하게 생각하는 부분에 따른 차이는 없었다. 피부 관리실 형태는 기타( $\mathrm{M}=3.51)$, 프랜차이즈 피부 관리실 $(\mathrm{M}=3.07)$, 일반 피부 관리실 $(\mathrm{M}=3.07)$, 피부과 제휴 피 부 관리실 $(\mathrm{M}=2.91)$ 순으로 기타 피부 관리실을 이용하는 응답자의 보상에 대한 만족도가 가장 높았고 $(F=4.242 ; p<0.01), 1$ 회 피부 관 리 비용은 5 만원 미만( $\mathrm{M}=3.21), 10$ 만원 이상( $\mathrm{M}=3.10), 5-10$ 만원 미 만(M=2.84) 순으로 5 만원 미만으로 피부 관리실을 이용하는 응답자 의 보상에 대한 만족도가 가장 높았다 $(F=10.016 ; p<0.001)$.

\section{1) 피부 관리실 이용형태에 따른 유형성의 차이}

피부 관리실 이용형태에 따른 유형성에 대한 만족도의 차이를 살 펴본 결과는 Table 6 와 같다. 유형성은 피부 관리실 형태와 1 회 피 부 관리 비용에 따른 차이는 유의미하였으나, 피부 관리실 정보습 득 경로, 방문 빈도, 보상에 대한 만족도에서 가장 중요하게 생각하 는 부분에 따른 차이는 유의수준 $5 \%$ 에서 유의미하지 않았다. 피부 관리실 형태는 기타( $\mathrm{M}=3.60)$, 프랜차이즈 피부 관리실(M=3.03), 일반 피부 관리실 $(\mathrm{M}=2.82)$, 피부과 제휴 피부 관리실 $(\mathrm{M}=2.82)$ 순 으로 기타 피부 관리실을 이용하는 응답자의 유형성에 대한 만족도 가 가장 높았고( $F=5.490 ; p<0.01), 1$ 회 피부 관리 비용은 5 만원 미만 $(\mathrm{M}=3.11), 10$ 만원 이상 $(\mathrm{M}=2.91), 5-10$ 만원 미만( $\mathrm{M}=2.68)$ 순으로 5 만원 미만으로 피부 관리실을 이용하는 응답자의 유형성에 대한 만
족도가 가장 높았다 $(F=8.675 ; p<0.001)$.

2) 피부 관리실 이용형태에 따른 신뢰성의 차이

피부 관리실 이용형태에 따른 신뢰성에 대한 만족도의 차이를 살 펴본 결과는 Table 7 와 같다. 신뢰성은 피부 관리실 형태와 1 회 피 부 관리 비용, 방문 빈도에 따른 차이는 유의미하였으나, 피부 관리 실 정보습득 경로, 보상에 대한 만족도에서 가장 중요하게 생각하는 부분에 따른 차이는 유의수준 $5 \%$ 에서 유의미하지 않았다. 피부 관 리실 형태는 기타( $\mathrm{M}=3.63)$, 일반 피부 관리실 $(\mathrm{M}=3.14)$, 프랜차이즈 피부 관리실 $(\mathrm{M}=3.03)$, 피부과 제휴 피부 관리실 $(\mathrm{M}=2.83)$ 순으로 신뢰성에 대한 만족도가 높았고 $(F=6.038 ; p<0.01), 1$ 회 피부 관리 비용은 5만원 미만( $\mathrm{M}=3.24), 10$ 만원 이상( $\mathrm{M}=3.11), 5-10$ 만원 미만 $(\mathrm{M}=2.81)$ 순으로 5 만원 미만으로 피부 관리실을 이용하는 응답자의 신뢰성에 대한 만족도가 가장 높았으며 $(F=9.379 ; p<0.001)$, 방문 빈 도는 주 2 회 이상 $(\mathrm{M}=3.47)$, 주 1 회( $\mathrm{M}=3.16)$, 월 2회 이상 $(\mathrm{M}=3.05)$, 기타(M=3.00), 월 1 회 $(\mathrm{M}=2.83)$ 순으로 주 2 회 이상 피부 관리실을 이용하는 응답자의 신뢰성에 대한 만족도가 가장 높은 것으로 나타 났다 $(F=4.004 ; p<0.01)$.

3) 피부 관리실 이용형태에 따른 반응성의 차이

피부 관리실 이용형태에 따른 반응성에 대한 만족도의 차이를 살펴본 결과는 Table 8 와 같다. 반응성은 1 회 피부 관리 비용에 따

\section{Table 6. Differences in satisfaction with respect to tangibility based on use pattern of skin care clinics}

\begin{tabular}{|c|c|c|c|c|c|c|c|}
\hline Category & & $\mathrm{N}$ & Mean & S.D. & $F$ & $p$ & Scheffe \\
\hline \multirow{4}{*}{ Information source } & Signs, brochures, or local flyers & 24 & 3.15 & 0.69 & \multirow{4}{*}{2.156} & \multirow{4}{*}{0.094} & \multirow{4}{*}{-} \\
\hline & Internet & 73 & 2.82 & 0.63 & & & \\
\hline & Recommendation by others & 76 & 2.84 & 0.76 & & & \\
\hline & Others & 27 & 3.08 & 0.67 & & & \\
\hline \multirow{4}{*}{ Skin care clinic type } & Franchise (a) & 36 & 3.03 & 0.64 & \multirow{4}{*}{$5.490^{* *}$} & \multirow{4}{*}{0.001} & \multirow{4}{*}{$d>a, b, c$} \\
\hline & General (b) & 83 & 2.82 & 0.70 & & & \\
\hline & Dermatologist affiliated (c) & 69 & 2.82 & 0.65 & & & \\
\hline & Others $(d)$ & 12 & 3.60 & 0.79 & & & \\
\hline \multirow{3}{*}{ One-time fee } & Less than 50,000 won (a) & 90 & 3.11 & 0.74 & \multirow{3}{*}{$8.675^{* * *}$} & \multirow{3}{*}{0.000} & \multirow{3}{*}{$a, c>c, b$} \\
\hline & $50,000-100,000$ won (b) & 86 & 2.68 & 0.64 & & & \\
\hline & More than 100,000 won (c) & 24 & 2.91 & 0.54 & & & \\
\hline \multirow{5}{*}{ Visit frequency } & Once a week & 35 & 2.84 & 0.79 & \multirow{5}{*}{1.227} & \multirow{5}{*}{0.301} & \multirow{5}{*}{-} \\
\hline & More than twice a week & 23 & 3.18 & 0.84 & & & \\
\hline & Once a month & 55 & 2.84 & 0.68 & & & \\
\hline & More than twice a month & 36 & 2.84 & 0.78 & & & \\
\hline & Others & 51 & 2.93 & 0.51 & & & \\
\hline \multirow{5}{*}{$\begin{array}{l}\text { Importance of } \\
\text { compensation satisfaction }\end{array}$} & Tangibility & 19 & 2.63 & 0.70 & \multirow{5}{*}{0.856} & \multirow{5}{*}{0.492} & \multirow{5}{*}{-} \\
\hline & Reliability & 79 & 2.96 & 0.63 & & & \\
\hline & Responsiveness & 44 & 2.92 & 0.89 & & & \\
\hline & Assurance & 23 & 2.89 & 0.80 & & & \\
\hline & Empathy & 35 & 2.89 & 0.50 & & & \\
\hline
\end{tabular}

S.D., standard deviation; ${ }^{* *} p<0.01 ;{ }^{* * *} p<0.001$. 
른 차이는 유의미하였으나, 피부 관리실 정보습득 경로, 피부 관리 실 형태, 방문 빈도, 보상에 대한 만족도에서 가장 중요하게 생각하 는 부분에 따른 차이는 없었다. 1 회 피부 관리 비용은 10 만원 이상 $(\mathrm{M}=3.26), 5$ 만원 미만( $\mathrm{M}=3.21), 5-10$ 만원 미만( $\mathrm{M}=2.96)$ 순으로 반 응성에 대한 만족도가 높은 것으로 나타났다 $(F=4.251 ; p<0.05)$.

\section{4) 피부 관리실 이용형태에 따른 보증성의 차이}

피부 관리실 이용형태에 따른 보증성에 대한 만족도의 차이를 살 펴본 결과는 Table 9 와 같다. 보증성은 피부 관리실 정보습득 경로 와 1 회 피부 관리 비용에 따른 차이는 유의미하였으나, 피부 관리 실 형태, 방문 빈도, 보상에 대한 만족도에서 가장 중요하게 생각 하는 부분에 따른 차이는 없었다. 피부 관리실 정보습득 경로는 타 인의 권유 $(\mathrm{M}=3.26)$, 간판/전단지 및 지역 정보지 $(\mathrm{M}=3.24)$, 기타 $(\mathrm{M}=3.01)$, 인터넷 $(\mathrm{M}=2.95)$ 순으로 보증성에 대한 만족도가 높았으 며( $F=2.945 ; p<0.05), 1$ 회 피부 관리 비용은 5 만원 미만(M=3.25), 10 만원 이상 $(\mathrm{M}=3.18), 5-10$ 만원 미만 $(\mathrm{M}=2.94)$ 순으로 보증성에 대 한 만족도가 높은 것으로 나타났다 $(F=4.625 ; p<0.05)$.

\section{5) 피부 관리실 이용형태에 따른 공감성의 차이}

피부 관리실 이용형태에 따른 공감성에 대한 만족도의 차이를 살 펴본 결과는 Table 10 와 같다. 공감성은 피부 관리실 형태와 1 회 피 부 관리 비용에 따른 차이는 유의미하였으나, 피부 관리실 정보습 득 경로, 방문 빈도, 보상에 대한 만족도에서 가장 중요하게 생각하 는 부분에 따른 차이는 없었다. 피부 관리실 형태는 기타( $\mathrm{M}=3.46)$,
프랜차이즈 피부 관리실 $(\mathrm{M}=3.15)$, 일반 피부 관리실 $(\mathrm{M}=3.08)$, 피부 과 제휴 피부 관리실 $(\mathrm{M}=2.93)$ 순으로, 피부과 제휴 피부 관리실 이 용자의 공감성에 대한 만족도가 가장 낮았고( $F=3.053 ; p<0.05), 1$ 회 피부 관리 비용은 5 만원 미만(M=3.24), 10 만원 이상( $\mathrm{M}=3.08), 5-10$ 만원 미만(M=2.88) 순으로 1 회 피부 관리 비용이 5 만원 미만인 응 답자의 공감성에 대한 만족도가 가장 높았다 $(F=8.103 ; p<0.001)$.

\section{Conclusion}

본 연구는 서울에 거주하는 여성을 대상으로 피부 관리실의 이용 형태가 보상에 대한 만족도에 미치는 영향에 대해 알아봄으로써 미 용 서비스의 관계 마케팅적 시사점을 얻고자 하였다. 연구 결과를 요약하면 다음과 같다.

첫째, 연령은 '21-30세’가 67.0\%, '31-40세’가 33.0\%이었고, 결혼 상태는 ‘미혼’이 $81.5 \%$, '기혼’이 $18.5 \%$ 이었다. 직업은 ‘학생’이 $48.0 \%$ 로 가장 많았고, '서비스직'이 $23.5 \%$, '전문직'이 $13.0 \%$, '사무직'이 $11.0 \%$, '전업주부'가 $2.5 \%$, '기타'가 $2.0 \%$ 순이었으며, 최종학력은 '대학교 재학/졸업'이 $64.0 \%$, '전문대학 재학/졸업'이 $29.0 \%$, '고등학 교 졸업'이 $7.0 \%$ 순으로 조사되었다.

둘째, 피부 관리실 이용형태에 따른 보상 만족의 차이로는 피부 관리실에 대한 정보습득으로는 '타인의 권유’가 $38.0 \%$ 로 가장 많았 고(Kwon, 2009), '일반 피부 관리실' $41.5 \%, 1$ 회 피부 관리 비용으 로는 ‘5-10만원 미만’이 43.0\%, 피부 관리실 방문 빈도는 ‘월 1회’가

\section{Table 7. Differences in satisfaction with respect to reliability based on use pattern of skin care clinics}

\begin{tabular}{|c|c|c|c|c|c|c|c|}
\hline Category & & $\mathrm{N}$ & Mean & S.D. & $F$ & $p$ & Scheffe \\
\hline \multirow{4}{*}{ Information source } & Signs, brochures, or local flyers & 24 & 3.08 & 0.71 & \multirow{4}{*}{2.239} & \multirow{4}{*}{0.085} & \multirow{4}{*}{-} \\
\hline & Internet & 73 & 2.91 & 0.61 & & & \\
\hline & Recommendation by others & 76 & 3.06 & 0.78 & & & \\
\hline & Others & 27 & 3.31 & 0.60 & & & \\
\hline \multirow{4}{*}{ Skin care clinic type } & Franchise & 36 & 3.03 & 0.59 & \multirow{4}{*}{$6.038^{* *}$} & \multirow{4}{*}{0.001} & \multirow{4}{*}{-} \\
\hline & General & 83 & 3.14 & 0.70 & & & \\
\hline & Dermatologist affiliated & 69 & 2.83 & 0.68 & & & \\
\hline & Others & 12 & 3.63 & 0.69 & & & \\
\hline \multirow{3}{*}{ One-time fee } & Less than 50,000 won (a) & 90 & 3.24 & 0.66 & \multirow{3}{*}{$9.379^{* * *}$} & \multirow{3}{*}{0.000} & \multirow{3}{*}{$a, c>c, b$} \\
\hline & $50,000-100,000$ won (b) & 86 & 2.81 & 0.69 & & & \\
\hline & More than 100,000 won (c) & 24 & 3.11 & 0.63 & & & \\
\hline \multirow{5}{*}{ Visit frequency } & Once a week (a) & 35 & 3.16 & 0.83 & \multirow{5}{*}{$4.004^{* *}$} & \multirow{5}{*}{0.004} & \multirow{5}{*}{$\begin{array}{l}\text { b, a, d, e } \\
>a, d, e, c\end{array}$} \\
\hline & More than twice a week (b) & 23 & 3.47 & 0.70 & & & \\
\hline & Once a month (c) & 55 & 2.83 & 0.73 & & & \\
\hline & More than twice a month (d) & 36 & 3.05 & 0.68 & & & \\
\hline & Others $(\mathrm{e})$ & 51 & 3.00 & 0.46 & & & \\
\hline \multirow{5}{*}{$\begin{array}{l}\text { Importance of } \\
\text { compensation satisfaction }\end{array}$} & Tangibility & 19 & 2.87 & 0.64 & \multirow{5}{*}{0.486} & \multirow{5}{*}{0.746} & \multirow{5}{*}{-} \\
\hline & Reliability & 79 & 3.05 & 0.71 & & & \\
\hline & Responsiveness & 44 & 3.13 & 0.73 & & & \\
\hline & Assurance & 23 & 3.03 & 0.78 & & & \\
\hline & Empathy & 35 & 3.01 & 0.62 & & & \\
\hline
\end{tabular}

S.D., standard deviation; ${ }^{* *} p<0.01 ;{ }^{* * *} p<0.001$. 
Table 8. Differences in satisfaction with respect to responsiveness based on use pattern of skin care clinics

\begin{tabular}{|c|c|c|c|c|c|c|c|}
\hline Category & & $\mathrm{N}$ & Mean & S.D. & $F$ & $p$ & Scheffe \\
\hline \multirow{4}{*}{ Information source } & Signs, brochures, or local flyers & 24 & 3.06 & 0.60 & \multirow{4}{*}{1.677} & \multirow{4}{*}{0.173} & \multirow{4}{*}{-} \\
\hline & Internet & 73 & 3.02 & 0.59 & & & \\
\hline & Recommendation by others & 76 & 3.24 & 0.73 & & & \\
\hline & Others & 27 & 3.05 & 0.60 & & & \\
\hline \multirow{4}{*}{ Skin care clinic type } & Franchise & 36 & 3.09 & 0.66 & \multirow{4}{*}{1.232} & \multirow{4}{*}{0.299} & \multirow{4}{*}{-} \\
\hline & General & 83 & 3.16 & 0.76 & & & \\
\hline & Dermatologist affiliated & 69 & 3.02 & 0.45 & & & \\
\hline & Others & 12 & 3.36 & 0.70 & & & \\
\hline \multirow{3}{*}{ One-time fee } & Less than 50,000 won & 90 & 3.21 & 0.68 & \multirow{3}{*}{$4.251^{*}$} & \multirow{3}{*}{0.016} & \multirow{3}{*}{-} \\
\hline & $50,000-100,000$ won & 86 & 2.96 & 0.60 & & & \\
\hline & More than 100,000 won & 24 & 3.26 & 0.59 & & & \\
\hline \multirow{5}{*}{ Visit frequency } & Once a week & 35 & 3.29 & 0.85 & \multirow{5}{*}{1.545} & \multirow{5}{*}{0.191} & \multirow{5}{*}{-} \\
\hline & More than twice a week & 23 & 3.20 & 0.76 & & & \\
\hline & Once a month & 55 & 3.14 & 0.60 & & & \\
\hline & More than twice a month & 36 & 3.06 & 0.63 & & & \\
\hline & Others & 51 & 2.96 & 0.45 & & & \\
\hline \multirow{5}{*}{$\begin{array}{l}\text { Importance of } \\
\text { compensation satisfaction }\end{array}$} & Tangibility & 19 & 3.00 & 0.74 & \multirow{5}{*}{0.201} & \multirow{5}{*}{0.938} & \multirow{5}{*}{-} \\
\hline & Reliability & 79 & 3.12 & 0.56 & & & \\
\hline & Responsiveness & 44 & 3.16 & 0.81 & & & \\
\hline & Assurance & 23 & 3.10 & 0.70 & & & \\
\hline & Empathy & 35 & 3.10 & 0.53 & & & \\
\hline
\end{tabular}

S.D., standard deviation; ${ }^{*} p<0.05$.

Table 9. Differences in satisfaction with respect to assurance based on use pattern of skin care clinics

\begin{tabular}{|c|c|c|c|c|c|c|c|}
\hline Category & & $\mathrm{N}$ & Mean & S.D. & $F$ & $p$ & Scheffe \\
\hline \multirow{4}{*}{ Information source } & Signs, brochures, or local flyers & 24 & 3.24 & 0.59 & \multirow{4}{*}{$2.945^{*}$} & \multirow{4}{*}{0.034} & \multirow{4}{*}{-} \\
\hline & Internet & 73 & 2.95 & 0.66 & & & \\
\hline & Recommendation by others & 76 & 3.26 & 0.72 & & & \\
\hline & Others & 27 & 3.01 & 0.80 & & & \\
\hline \multirow{4}{*}{ Skin care clinic type } & Franchise & 36 & 3.06 & 0.61 & \multirow{4}{*}{1.784} & \multirow{4}{*}{0.152} & \multirow{4}{*}{-} \\
\hline & General & 83 & 3.17 & 0.81 & & & \\
\hline & Dermatologist affiliated & 69 & 3.00 & 0.54 & & & \\
\hline & Others & 12 & 3.44 & 0.99 & & & \\
\hline \multirow{3}{*}{ One-time fee } & Less than 50,000 won & 90 & 3.25 & 0.73 & \multirow{3}{*}{$4.625^{*}$} & \multirow{3}{*}{0.011} & \multirow{3}{*}{-} \\
\hline & $50,000-100,000$ won & 86 & 2.94 & 0.69 & & & \\
\hline & More than 100,000 won & 24 & 3.18 & 0.57 & & & \\
\hline \multirow{5}{*}{ Visit frequency } & Once a week & 35 & 3.25 & 0.85 & \multirow{5}{*}{1.059} & \multirow{5}{*}{0.378} & \multirow{5}{*}{-} \\
\hline & More than twice a week & 23 & 3.25 & 1.06 & & & \\
\hline & Once a month & 55 & 3.02 & 0.63 & & & \\
\hline & More than twice a month & 36 & 3.16 & 0.65 & & & \\
\hline & Others & 51 & 3.01 & 0.49 & & & \\
\hline \multirow{5}{*}{$\begin{array}{l}\text { Importance of } \\
\text { compensation satisfaction }\end{array}$} & Tangibility & 19 & 2.75 & 0.76 & \multirow{5}{*}{1.577} & \multirow{5}{*}{0.182} & \multirow{5}{*}{-} \\
\hline & Reliability & 79 & 3.13 & 0.63 & & & \\
\hline & Responsiveness & 44 & 3.22 & 0.85 & & & \\
\hline & Assurance & 23 & 3.17 & 0.60 & & & \\
\hline & Empathy & 35 & 3.07 & 0.70 & & & \\
\hline
\end{tabular}

S.D., standard deviation; ${ }^{*} p<0.05$. 
$27.5 \%$, 보상에 대한 만족도에서 가장 중요하게 생각하는 부분으로 는 '신뢰성'이 $39.5 \%$ 로 만족이 가장 높았다.

셋째, 보상 만족도의 기술통계는 전체의 평균은 3.04로, '반 응성' $(\mathrm{M}=3.11)$, ‘보증성' $(\mathrm{M}=3.11)$, ‘공감성' $(\mathrm{M}=3.06)$, '신뢰성' $(\mathrm{M}=3.04)$, '유형성' $(\mathrm{M}=2.90)$ 순으로 보상 만족의 평균이 높았다.

넷째, 피부 관리실 이용형태에 따른 보상 만족도의 차이로는 피 부 관리실 형태와 1 회 피부 관리 비용에 따른 보상 만족도의 차이 는 유의미하였으나, 정보습득 경로, 방문 빈도, 보상에 대한 만족 도에서 가장 중요하게 생각하는 부분에 따른 차이는 없었다. 유형 성은 피부 관리실 형태는 기타( $\mathrm{M=}=3.60)$ 로 이는 현재 피부 관리실 이 다양한 프로그램과 함께 심미적인 마케팅으로 고객을 만족시 키고 있다는 선행논문과 같은 결과가 나왔다(Son et al., 2009). 프 랜차이즈 피부 관리실(M=3.03), 1 회 피부 관리 비용은 5 만원 미만 $(\mathrm{M}=3.11)$ 로 피부 관리실 형태와 1 회 피부 관리 비용에 따른 차이는 유의미하였으나, 피부 관리실 정보습득 경로, 방문 빈도, 보상에 대 한 만족도에서 가장 중요하게 생각하는 부분에 따른 차이는 유의수 준 $5 \%$ 에서 유의미하지 않았다.

최근 피부 관리실은 고객 만족도를 높이기 위해 전문가들의 조 언을 얻어 프로그램을 적용하고 있다. 아울러 피부 관리실 프랜차 이즈들은 이런 교육과정이 관리실을 운영하는 중요한 부분이며, 직 원 교육 및 관리 프로그램을 체계화하는 것으로 고객의 신뢰를 높 일 수 있다고 말하고 있다(Kim \& Lee, 2015; Park et al., 2009).
신뢰성은 피부 관리실 형태는 기타( $M=3.63)$, 일반 피부 관리실 $(\mathrm{M}=3.14), 1$ 회 피부 관리 비용은 5 만원 미만(M=3.24), 방문 빈도는 주 2 회 이상 $(\mathrm{M}=3.47)$ 으로, 피부 관리실 형태와 1 회 피부 관리 비 용, 방문 빈도에 따른 차이는 유의미하였으나, 피부 관리실 정보습 득 경로, 보상에 대한 만족도에서 가장 중요하게 생각하는 부분에 따른 차이는 유의수준 5\%에서 유의미하지 않았다. 피부 관리실 신 뢰성은 고객 관리의 중요한 요소로 생각되며(Jeong \& YoO, 2003), 고객을 위한 관리실의 신뢰성은 보상처리의 방법, 불량 서비스 시 제공되는 보상 프로그램에 대한 신뢰, 예약시간을 우선으로 한다는 결과와 일치한다.

반응성은 1 회 피부 관리 비용은 10 만원 이상 $(\mathrm{M}=3.26)$ 으로 유의 미하였으나, 피부 관리실 정보습득 경로, 피부 관리실 형태, 방문 빈도, 보상에 대한 만족도에서 가장 중요하게 생각하는 부분에 따 른 차이는 없었다. 보증성은 피부 관리실 정보습득 경로는 타인의 권유 $(\mathrm{M}=3.26)$ 로, 피부 관리실 정보습득 경로와 1 회 피부 관리 비용 에 따른 차이는 유의미하였으나, 피부 관리실 형태, 방문 빈도, 보 상에 대한 만족도에서 가장 중요하게 생각하는 부분에 따른 차이 는 없었다. 보증성은 관리자의 말, 행동에 대한 믿음은 타인의 권 유에 의한 확실한 보증으로 고객확보의 방법이 된다는 것을 입증한 다(Lee, 2008). 공감성은 피부 관리실 형태는 기타(M=3.46), 프랜 차이즈 피부 관리실 $(\mathrm{M}=3.15)$ 로, 피부 관리실 형태와 1 회 피부 관리 비용에 따른 차이는 유의미하였으나, 피부 관리실 정보습득 경로,

\section{Table 10. Differences in satisfaction with respect to empathy based on use pattern of skin care clinics}

\begin{tabular}{|c|c|c|c|c|c|c|c|}
\hline Category & & $\mathrm{N}$ & Mean & S.D. & $F$ & $p$ & Scheffe \\
\hline \multirow{4}{*}{ Information source } & Signs, brochures, or local flyers & 24 & 3.19 & 0.55 & \multirow{4}{*}{0.726} & \multirow{4}{*}{0.537} & \multirow{4}{*}{-} \\
\hline & Internet & 73 & 2.99 & 0.58 & & & \\
\hline & Recommendation by others & 76 & 3.10 & 0.69 & & & \\
\hline & Others & 27 & 3.06 & 0.57 & & & \\
\hline \multirow{4}{*}{ Skin care clinic type } & Franchise (a) & 36 & 3.15 & 0.54 & \multirow{4}{*}{$3.053^{*}$} & \multirow{4}{*}{0.030} & \multirow{4}{*}{$\begin{array}{c}d, a, b \\
>a, b, c\end{array}$} \\
\hline & General (b) & 83 & 3.08 & 0.64 & & & \\
\hline & Dermatologist affiliated (c) & 69 & 2.93 & 0.60 & & & \\
\hline & Others $(\mathrm{d})$ & 12 & 3.46 & 0.66 & & & \\
\hline \multirow{3}{*}{ One-time fee } & Less than 50,000 won (a) & 90 & 3.24 & 0.60 & \multirow{3}{*}{$8.103^{* * *}$} & \multirow{3}{*}{0.000} & \multirow{3}{*}{$a, c>c, b$} \\
\hline & $50,000-100,000$ won (b) & 86 & 2.88 & 0.60 & & & \\
\hline & More than 100,000 won (c) & 24 & 3.08 & 0.59 & & & \\
\hline \multirow{5}{*}{ Visit frequency } & Once a week & 35 & 3.11 & 0.72 & \multirow{5}{*}{1.859} & \multirow{5}{*}{0.119} & \multirow{5}{*}{-} \\
\hline & More than twice a week & 23 & 3.36 & 0.55 & & & \\
\hline & Once a month & 55 & 2.96 & 0.68 & & & \\
\hline & More than twice a month & 36 & 3.07 & 0.64 & & & \\
\hline & Others & 51 & 3.01 & 0.46 & & & \\
\hline \multirow{5}{*}{$\begin{array}{l}\text { Importance of } \\
\text { compensation satisfaction }\end{array}$} & Tangibility & 19 & 2.96 & 0.46 & \multirow{5}{*}{1.587} & \multirow{5}{*}{0.179} & \multirow{5}{*}{-} \\
\hline & Reliability & 79 & 3.16 & 0.54 & & & \\
\hline & Responsiveness & 44 & 3.12 & 0.75 & & & \\
\hline & Assurance & 23 & 2.99 & 0.71 & & & \\
\hline & Empathy & 35 & 2.88 & 0.60 & & & \\
\hline
\end{tabular}

S.D., standard deviation; ${ }^{*} p<0.05 ;{ }^{* * *} p<0.001$. 
방문 빈도, 보상에 대한 만족도에서는 유의미한 차이가 없었다. 이 는 다른 피부 관리실과는 구별되는 차별화 관리, 보상을 위한 종사원 의 빠른 처리 방법이 고객의 만족을 높이는 결과가 됨을 입증한다.

본 연구의 제안점은 다음과 같다.

첫째, 본 연구는 표본 선정에 있어 일부 지역의 피부 관리실만으 로 표본을 선정했다는 점에서 한계가 있어, 좀 더 구체적으로 메디 컬 스파, 호텔 스파, 리조트 스파 등의 미용 산업에 대해 더욱 연구 가 필요할 것으로 사료된다.

둘째, 피부 관리실을 이용하는 여성뿐 아니라 남성의 피부 관리 성향을 구체적으로 연구함으로써 피부 미용 산업의 발전을 가져올 것이라 사료된다.

\section{References}

Choi JM, Yoo YJ. A study of factors which have influence on the customer satisfaction and re-visit willingness of skin care shop: focusing on the results of a survey of college student perception. The Journal of Korean Policy Studies, 12: 569-589, 2012.

Dowling GR, Uncles M. Do customer loyalty programs really work? MIT Sloan Management Review, 38: 71-82, 1997.

Jang WJ, Choi KJ. The present condition of skin care shop in Jeju island \& capital circle. Journal of the Korean Society of Beauty and Art, 7: 195-215, 2006.

Jegal M, Kim JD. Attitudes \& perceptions on the professional skin care among working women. Journal of the Korean Society of Cosmetology, 9: 122-136, 2003.

Jeong MK, Yoo WK. The study of the use of cosmetics and skin care of middle-aged women in Young-nam province. Journal of the Korean Society of Fashion \& Beauty, 1: 4964, 2003.

Jong SU, Kim SN. The effect on customer satisfaction from compensation for inappropriate service of skin care shop: focusing on the mediated effect of human services. Asian Journal of Beauty and Cosmetology, 13: 65-73, 2015.

$\mathrm{Kim} \mathrm{JH}$, Lee EH. The effect of skin health care for middle age women's appearance satisfaction. Journal of Beauty Art Management, 9: 67-75, 2015.

Kim KY, Jin KN. The effect of foreign patients' expectation and experience on the satisfaction of medical service. Korean Journal of Hospital Management, 18: 1-17, 2013.

Kim NY. A study on consumer satisfaction in skin care shops according to consumers' characteristics: focused on capital areas. Asian Journal of Beauty and Cosmetology, 8: 313-326, 2010.

KOSIS (Statistics Korea, 2013 The service industry survey), 2014.12.

Kwon HY. A study on skincare service preference and customer satisfaction. Journal of the Korean Society of Esthetics \& Cosmeceutics, 4: 85-106, 2009.

Lee JS, Jang HJ. Impacts of hotel employee's service quality on service value and visitor's attitude. Journal of Hospitality and Tourism Studies, 39: 266-276, 2010.

Lee JS. The research on the actual conditions of skin care of career women in 20 40's. The Journal of the Korean Society of Make-up Design, 4: 183-192, 2008.

Lee JY. The analysis of skin care service marketing-mix factor of skin care shops satisfaction and loyalty. Asian Journal of Beauty and Cosmetology, 13: 873-881, 2015.

Lee YH, Bae HS. The study on actual conditions and satisfactions of skin care salons in Korean who residence in the United States. Journal of the Korean Society of Cosmetology, 17: 880-888, 2011.

Park HR, Lee SN, Hong YH. Study of the practice of weight manegement attitude by middle-aged women. Asian Journal of Beauty and Cosmetology, 7: 107-122, 2009.

Park JH. Study on analysis of a beauty service employee's quality and priority order of competence evaluation factors. Asian Journal of Beauty and Cosmetology, 13: 903-908, 2015.

Son HJ, Kim JD, Kim EJ. A study on women's actual use of skin care shop and their satisfaction. Journal of the Korean Society of Cosmetology, 15: 77-99, 2009. 


\section{국문초록}

\section{여성들의 피부 관리실 이용형태에 따른 보상 만족도 차이에 관한 연구}

신미숙

원광대학교 뷰티디자인학과, 전라북도 익산시, 한국

목적: 본 연구는 피부 관리실의 이용형태에 따른 보상 만족에 대한 영향을 알아봄으로써 관리실의 질적 향상을 높이고 관리실의 보 상 프로그램을 체계화하여 고객에 대한 올바른 서비스를 제공하며, 이를 바탕으로 한 교육 자료를 관리실 및 창업을 위한 마케팅으 로 적극 활용하여 고객에 대한 신뢰 향상을 목적으로 한다. 방법: 본 연구를 수행하기 위한 자료 수집은 2015년 7월 6일부터 9월 5 일까지 총 2 개월간에 걸쳐 진행되었다. 모집단은 서울에 거주하며 피부 관리실을 이용하는 성인 여성을 대상으로 설문지를 배포하 였다. 배포한 총 282 부 중 82 부의 부적합한 설문지를 제외하고 200 부를 회수하여 최종 자료로 사용하였다. 결과: 피부 관리실 이 용형태에 따른 보상 만족도의 차이로는 피부 관리실 형태와 1 회 피부 관리 비용에 따른 보상 만족도의 차이는 유의미하였으나 반면 정보습득 경로, 방문 빈도는 보상에 대한 유의미한 차이는 없었다. 결론: 피부 관리시의 이용형태에 따른 보상 만족도를 높이기 위 해서는 기존의 유형성, 반응성 및 보증성을 높이기 보다는 신뢰성과 공감성을 보완하여 보상에 대한 만족도를 높여야 한다.

핵심어: 피부 관리실, 보상 만족도, 보상 프로그램, 신뢰성, 반응성

\section{참고문헌}

권혜영. 고객의 피부관리실 이용행태와 서비스 향상 방안 연구. 한국피부미용향장학회지, 4: 85-106, 2009.

김기영, 진기남. 외국인 환자의 기대수준과 경험수준이 의료서비스 만족도에 미치는 영향. 병원경영학회지, 18: 1-17, 2013. 김남연. 고객의 특성에 따른 피부관리실 고객만족도연구: 수도권을 중심으로. 아시안뷰티화장품학술지, 8: 313-326, 2010. 김지현, 이은희. 중년여성의 피부건강관리가 외모만족도에 미치는 영향. 한국미용예술경영학회지, 9: 67-75, 2015. 박지혜. 미용서비스종사자의 자질 및 역량 평가요인 우선순위 분석에 대한 연구. 아시안뷰티화장품학술지, 13: 903-908,

2015 .

박혜란, 이성내, 홍양희. 중년 여성의 체중 관리 실천 태도에 관한 연구. 아시안뷰티화장품학술지, $7: 107-122,2009$. 손현진, 김주덕, 김은주. 일부 지역 여성들의 일반적 특성에 따른 피부관리실 이용 실태 및 만족도에 관한 연구. 한국미용학회

지, 15: 77-99, 2009.

이유현, 배현숙. 미국 거주 한인들의 피부 관리실 이용실태와 만족도에 관한 연구. 한국미용학회지, 17: 880-888, 2011.

이장성, 장현종. 호텔직원의 인적서비스 품질특성이 서비스 가치 및 방문객 태도에 미치는 영향. 호텔관광연구, 39: 266-276, 2010. 이종신. 20 40대 직장여성의 피부 관리 실태에 관한 연구. 한국메이크업디자인학회지, 4: 183-192, 2008.

이지영. 피부관리실 만족 및 충성도에 영향을 미치는 피부미용서비스 마케팅믹스 요인 분석. 아시안뷰티화장품학술지, 13:

873-881, 2015.

장원정, 최금주. 제주도와 수도권 피부관리실의 현황에 관한 연구. 한국인체미용예술학회지, 7: 195-215, 2006.

정민경, 유왕근. 영남 지역 중년여성의 화장품 사용 및 피부관리 실태 파악 연구. 한국패션뷰티학회지, 1: 49-64, 2003.

제갈명, 김주덕. 직장여성들의 피부관리에 대한 인식 및 태도. 한국미용학회지, 9: 122-136, 2003.

종서우, 김성남. 피부 관리실의 부적절한 서비스에 대한 보상이 고객만족에게 미치는 영향: 인적서비스의 매개효과를 중심으

로. 아시안뷰티화장품학술지, 13: 65-73, 2015.

최재민, 유유정. 피부관리실 이용자 만족도 및 재방문의사 결정요인에 대한 연구: 대학생의 인식조사결과를 중심으로. 한국정

책연구, 12: 569-589, 2012.

KOSIS (통계청, 2013 서비스업조사), 2014.12. 


\section{中文摘要}

\section{女性皮肤美容院的使用模式对补偿满意度差异的研究}

申美淑

圆光大学美容设计学科, 全罗北道益山市，韩国

目的：探讨皮肤美容院的使用模式对补偿满意度的影响，从而提高美容院的设施质量，进行系统化补偿项目，提供正确 的服务。这些教育资料将被美容院和初创公司用来作为培训材料和营销帮助, 以建立他们对客户的信任。方法: 数据收 集时间为2015年7月6日至9月5日，为期两个月。对居住在首尔并利用皮肤美容院的成年女性进行了问卷调查，在发放的 282份问卷中，排除了82份不符合的问卷，以200份问卷作为最终数据使用。结果：根据皮肤美容院使用模式的补偿满意 度差异, 发现皮肤美容院模式和一次性费用对补偿满意度有显著影响, 相反获得信息途径和访问频率对补偿没有显著影 响。结论：为提高根据皮肤美容院的使用模式的补偿满意度，有必要补充可靠性和共感性而不是提高以前的类型性，反 应性和保证性。

关键词: 皮肤美容院，补偿满意度，补偿项目，可靠性，反应性 